\title{
Contextos postos e pressupostos: o lugar do histórico e do mítico na obra de Jorge Luís Borges
}

\author{
EDWARD LOPES \\ (Professor Titular do Instituto de Letras, \\ Ciências Sociais e Educaçāo da UNESP - \\ Departamento de Literatura)
}

\section{Isotopias figurativas: sentido contextual}

É tentadora a idéia de conceber a isotopia da mensagem como o sentido contextualmente construído por meio do mecanismo da citação. Nessa orden de idéas, poder-se-ia afirmar que qualquer parte de um discurso cita alguma outra, funcionando uma delas como um relatum citante e a outra como o seu correlato citado:

- o relatum citante localiza-se como um segmento segundo, $\mathrm{sg}^{2}$, naquela parte do discurso que se está a ler como isto (= este assunto), aqui e agora, que leio neste preciso instante da enunciação;

- o correlato citado localiza-se como um primeiro segmento, $\mathrm{sg} 1$, que percebemos, ao ler o relato citante do $\mathrm{sg}^{2}$, como aquilo (= aquele assunto) que li (ou que lerei), lá, entāo, no contexto do discurso X (Dx).

E através da citação isotópica que vem a realizar-se, sintagmatizando-se na mensagem, a replicabilidade, essa propriedade paradigmática do c6digo que possibilita a construção do texto mediante a interpretaçāo de uma parte da mensagem por outra parte. Assim, o sentido do relato citante, o sg${ }^{2}$ do discurso $\mathrm{Dx}$, é dado por sua relaçāo com o correlato citado, o sg1, que se toma como o contexto de Dx. E, como tudo o que tem sentido exprime-se no mínimo duas vezes no interior da mesma mensagem (o que se exprime uma única vez não tem sentido), diremos que toda e qualquer parte de um discurso só adquire uma forma e um sentido quando a interpretamos, na prática significante da leitura, como uma replica, que opera a metamorfose reconfigurativa de alguma outra parte do contexto da mesma mensagem.

Nestes termos, a réplica ( $\left.\mathrm{sg}^{2}\right)$ constitui uma referência para um referente (o sg1) portador da informação contida em um contexto que ela, réplica, se encarrega de interiorizar no discurso da mensagem.

Mas, se o lugar da referência não causa nenhum problema, uma vez que ela se define no próprio segmento-objeto que se está a ler, a cada instante, como isto, aqui e agora, já o lugar do referente varia na dependência da variação dos contextos que localizemos para o discurso Dx.

No nosso modo de ver, os discursos contêm contextos postos e contextos pressupostos:

- o contexto pressuposto de um discurso Dx é outro discurso, Dy; em sentido amplo, todos os demais discursos (Dy, $\mathrm{Dz}, \ldots, \mathrm{Da}, . .$.$) com os$ 
quais Dx se articula para constituir a totalidade de uma cultura (uma cultura = todos os discursos, verbais e gestuais, produzidos por uma comunidade); e, de modo mais restrito, é contexto pressuposto ocorrencial de um discurso Dx todo e qualquer outro discurso, Dy, que Dx cite, direta ou indiretamente, e do qual nos lembremos perante Dx, associandoo a ele, por estar, esse outro discurso Dy, estocado em nossa competência de enunciatários como referente atual de Dx, em nossa cultura (atual = pronto, em vigência e disponivel em competência);

- o contexto posto de um segmento do discurso Dx é outro segmento do mesmo discurso Dx, quer dizer, todos os demais segmentos que em Dx restaram depois que dele extraímos, por meio de nossa performance interpretativa, o segmento $\left(\mathrm{sg}^{2}\right)$ cujo referente $\left(\mathrm{sg}^{1}\right)$ queremos conhecer.

Sendo referência, assim, o segmento que se está a ler como operador da recuperação de uma informação citada, originalmente contida em um contexto, e sendo referente, por conseguinte, a informaçáo recuperada de um contexto (nunca uma "coisa da realidade extradiscursiva" como pensa a falácia realista), podemos reconhecer dois diferentes tipos de referentes, conforme sejam eles segmentos correlatos de um contexto posto ou pressuposto:

1 - O sgl que provenha de um contexto pressuposto (i. e, de outro discurso), constitui um referente intertextual para a referência do $\mathrm{sg}^{2}$, em Dx;

1.1 - Da articulação da referência com um referente intertextual resulta um intertexto, que funciona, na textualizaçăo, como o interpretante do contexto pressuposto da referência $\left(\mathrm{sg}^{2}\right)$ :

\begin{tabular}{|c|c|c|c|c|}
\hline Interpretante & & $S g^{1 / D y /}$ & $\boldsymbol{v s}$ & $S g^{2} / D x \mid$ \\
\hline $\begin{array}{l}\text { do contexto } \\
\text { pressuposto (ou }\end{array}$ & $=$ & & & \\
\hline $\begin{array}{l}\text { intertexto) do } \\
s g^{2}\end{array}$ & & $\begin{array}{l}\text { Referência } \\
\text { no } D x\end{array}$ & ws & $\begin{array}{c}\text { Referente } \\
\text { Intertextual } \\
\text { no Dy }\end{array}$ \\
\hline
\end{tabular}

1.2 - A referéncia que $E$ réplica do plano de conteúdo de um referente intertextual constitui uma parafrase intertextual; a 、 que for réplica do seu plano de expressão, constitui um paragrama intertextual;

2 - O sgl proveniente de um contexto posto (= de outra parte do mesmo discurso, Dx) constitui um referente intratextual para a referência $\mathrm{sg}^{2}$, em Dx;

2.1 - A articulação da referência com um referente intratextual produz um intratexto, que funciona, na textualização, como o interpretante do contexto posto da referência $\left(\mathrm{sg}^{2}\right)$ :

$\begin{aligned} & \text { Interpretante } \\ & \text { do contexto } \\ & \text { posto (ou in- } \\ & \text { tratexto) do } \mathrm{sg}^{2}\end{aligned}$
$\begin{array}{llll} & S g^{2} / D x / & \text { vs } & \frac{S g 1 / D x /}{\downarrow} \\ \text { Referência } & \text { vo } D x & \text { Referente } \\ \text { Intratextual } \\ \text { no } D x\end{array}$


2.2 - A referência que é réplica do plano de conteúdo de um referente intratextual constitui uma paráfrase intratextual; a que for réplica do seu plano de expressão, constitui um paragrama intratextual;

3 - A função referencial, com que vamos nos preocupar neste trabalho, é constituída de parafrases intertextuais e intratextuais (não nos deteremos, pois, na consideração da função poética, constitufda de paragramas inter e intratextuais).

Eis um resumo visual de quanto se viu até aqui:

\section{Citação Isotópica}

$$
S g^{2}-\text { REFERENCIA }
$$

A figura-ocorrencial que, como isto que se le, aqui e agora, recupera a informaçāo contida no $\mathrm{Sg}^{\mathrm{I}}$, interiorizando no Dx.

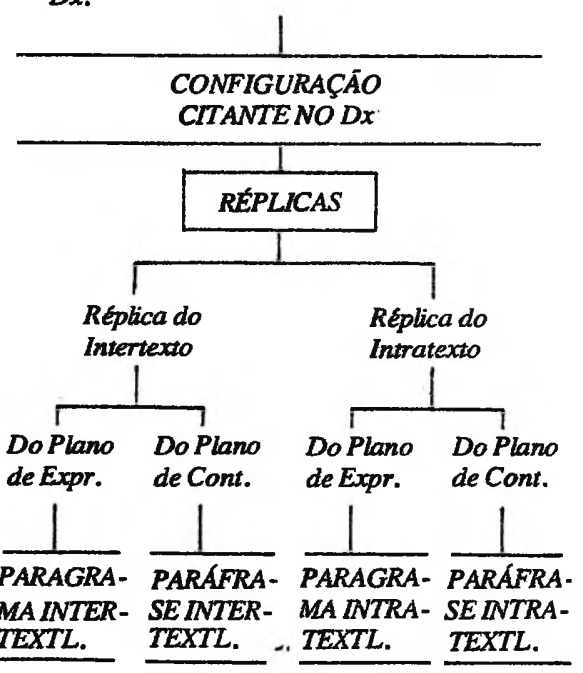

$S g^{1}-R E F E R E N T E$

A figura-tipo que se recorda, ao ler o $S g^{2}$ da referência, como aquilo que se leu, la, então, no $S_{g}$, como figuração citada no contexto de $\mathrm{Dx}$

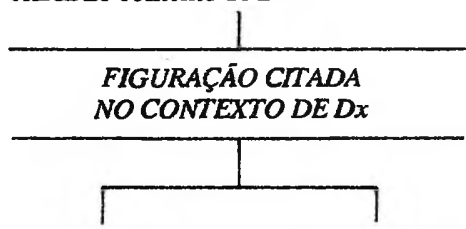

Figuração citada em outra parte do mesmo Figuração citadiscurso $D x$

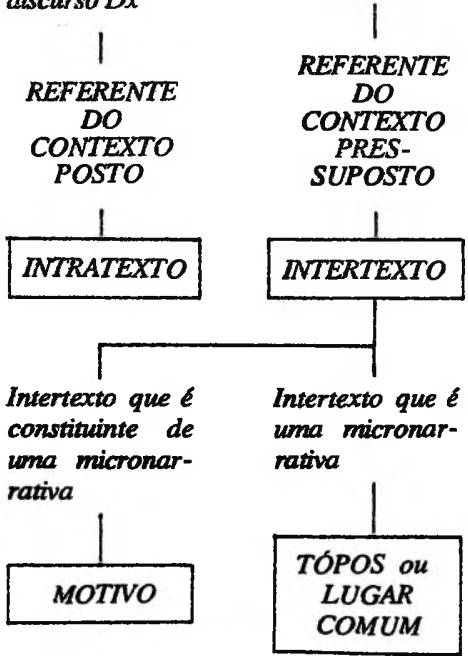

Fig. 1 -O Mecanismo Dialógico da Citaçāo Isotópica 
Deixando de lado, no restante do artigo, os paragramas, vamos nos ater unicamente às paráfrases, réplicas do plano de conteúdo dos referentes inter e intratextuais dos contos de Jorge Luís Borges.

\section{Contextos pressupostos: o lugar de inscrição do mítico em Borges}

Utilizando a Fig. 1, acima, como modelo operacional, podemos isolar dois diferentes referentes ( $\mathrm{sg}^{1}$ ) para a obra de Borges, conforme os localizemos no interior do mesmo discurso - referente intratextual, do contexto posto - ou de outro discurso - referente intertextual, do contexto pressuposto.

Vejamos, inicialmente, o conto intitulado La Otra Muerte. Nele se conta que um entrerriano natural de Gualeguay, Pedro Damián, portou-se como um covarde na batalha de Masoller, em 1904, da qual escapou para nela voltar a combater, nas imagens do delírio que precedeu a sua morte, em 1946, quando, sonhando-se na figura de um herói, Damián comandou a carga final da cavalaria e foi mortalmente baleado no peito.

Escolhendo como $\mathrm{sg}^{2}$, relato citante, de referência, o segmento da morte de Damián como um herói, na batalha de 1946, identificamos:

- como referente intratextual, sg1, citado, o segmento que narra a morte de Damián como um covarde, na batalha "real" de 1904.

A articulação

$$
S g^{2} / D x / \quad \text { vs } \quad S g 1 / D x /
$$

constrói o interpretante do contexto posto, que fixa a interpretação:

a morte de Damián em 1946 anula a morte dele em 1904, permitindo-lhe passar de covarde a valente, o que é um modo de recuperar a imagem heróica da sua antiga identidade,

que dá o sentido posto da referência $\left(\mathrm{sg}^{2}\right)$.

É o que consta, aliás, no dizer do narrador borgiano:

"Damián se portó como un cobarde en el campo de Masoller, y dedicó la vida a corregir esa bochornosa flaqueza (...). Penso (...): Si el destino me trae otra batalla, yo sabré merecerla. (...) y el destino al fin se la trajo, en la hora de su muerte. La trajo en forma de delirio (...). En la agónia revivió su batalla, y se condujo como un hombre y encabezó la carga final y una bala lo acertó en pleno pecho. Así, en 1946, por obra de una larga pasión, Pedro Damián murí́ en la derrota de Masoller, que ocurrió entre el invierno y la primavera de 1904."

(La Otra Muerte) 
- como referente intertextual, sgl, citado, o segmento que alude, através dos gritos de guerra, a outro discurso, Dy, que trata das batalhas de Cagancha e Índia Muerta, travadas há um século atrás:

"Algo me hizo preguntar qué gritaba el gurt Damián. - Malas palabras - dijo el coronel

-, que es to que se grita en las cargas.

- Puede ser - dijo Amaro -, pero también grit6" Viva Urquizal"

Nos quedamos callados. Al fin, el coronel murmuro:

- No como si peleara en Masoller, sino en

Cagancha o Índia Muerta, hara un siglo."

A articulação da referência com o referente, ou seja,

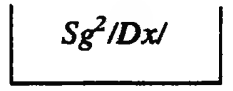

morte de Damián como un herói, no delírio de 1946 vs

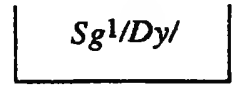

grito de "Urquizar"

nas batalhas de Cagancha

e Índia Muerta, de um século atrás

constró $o$ interpretante do contexto pressuposto, que fixa a interpretaçäo:

a batalha heróica de Damián em 1946 reproduz as batalhas de Martín Fierro, de um século atrás, permitindo-lhe, reconvertido de covarde em valente, recuperar a imagem heróica da sua identidade social - quer dizer, mítica - de gaúcho,

o que constitui o sentido pressuposto da referência, sg1 (coisa, de resto, que Explicitamente homologada pelo narrador de La Otra Muerte:

\section{"Damian, como gaucho, tenía obligación de ser Martin Fierro."}

Os contextos pressupostos das ficçōes de Borges incluem, como este acima demonstra, muitas vezes um fazer primordial, quer dizer, o gesto fundador de uma divindade, um ser mítico ou um herói que, por considerar-se autor de uma performance exemplar exprime, nela, um modelo de comportamento para os atores de um relato, que reproduzirāo esse fazer ao viver sua própria história. Veja-se, a propósito, o jogo referencial tramado entre a referência $\left(\mathrm{sg}^{2}\right)$ de Borges e o referente intertextual (sg1), de José Hernández: 
REFERENCIA, em Borges $S g^{2}$ : "De Alguien a Nadie" In: Otras Inquisiciones

"Un gaucho alza a un moreno con el cuchillo,

lo tira como un saco de huesos,

lo ve agonizar y morir,

se agacha para limpiar el acero, desata su caballo

$y$ monta despacio, para que no piensen que huye."
REFERENTE INTERTEXTUAL, em Hernández

$S g^{J}$ : Martín Fierro, VII

"Por fin, en una topada en el cuchillo lo alcé

y como un saco de güesos contra el cerco lo largué.

Tiró unas cuántas patadas y ya cantó pa el carnero. Nunca me pude olvidar de la agonía de aquel negro.

Limpié el facón en los pastos, desaté mi redomón,

monté despacio y salí al tranco pa el cañadón."

Através do procedimento dessa reescritura, Borges monta, em seus relatos, verdadeiras metamorfoses reconfigurativas de nobres e antigos arquétipos míticos. Repetindo o arquétipo gestual fundado no fazer primordial do ente mítico, $o$ ator humano de Borges se desliga do tempo profano, do espaço imanente, e entra em contato com o tempo mítico, do espaço transcendente, divino. Como diz o narrador, na continuação do trecho:

"..para que no piensen que huye. Esto que fue una vez vuelve a ser, infinitamente; los visibles ejércitos se fueron y queda un pobre duelo a cuchillo, el sueño de uno es parte de la memoria de todos."

("De Alguien a Nadie")

A reiteraçāo do gesto primordial, ocorrido in illo tempore, anterior mesmo à fundação da temporalidade, transpōe o ator humano para a temporalidade transtemporal - a duraçâo - do mito. Fundindo-se, aqui, todos os tempos, é comum que surjam, então, relacionados a eles, vários contextos pressupostos. É o caso do trecho a seguir, em que vemos fusionarem-se quatro contextos pressupostos, um na alusão ao segmento de abertura da I Parte do Quixote:

REFERENCIA, em Borges

$S g^{2}:$ Historia de la Eternidad:

"Una suerte de gravitación familiar me alejo hacia unos barrios de cuyo nombre quiero siempre acordarme(...)."
REFERENTE INTERTEXTUAL, em Cervantes

$S g^{1}$ : Don Quijote $(I, 1)$ :

"En un lugar de la Mancha, de cuyo nombre no quiero acordarme (...)." 
outro na menção explícita ao espảço anterior aos tempos da Conquista, "barro de América no conquistada aún", o terceiro na declaração "estoy en mil ochocientos y tantos", e o quarto na afirmativa "esto es lo mismo de hace treinta años:

"La tarde que precedió a esa noche, estuve en Barracas (...). Su noche no tenía destino alguno; como era serena, sall a caminar y recordar (...). Una suerte de gravitación familiar me alej6 hacia unos barrios de cuyo nombre quiero siempre acordarme (...). No quiero significar asi el barrio mío, el preciso ámbüto de la infancia, sino sus todavía misteriosas inmediaciones; confin que he poseido entero en palabras y poco en realidade, vecino y mitológico a un tiempo. (...). La marcha me dejó en una esquina (...). La vision (...) parecía simplificada por mi cansancio. La irrealizaba su misma tipicidad. La calle era de barro elemental, barro de América no conquistada aún. (...). Me quedé mirando esa sencillez. Pensé (...): Esto es lo mismo de hace treinta ańos (...) en ese ya vertiginoso silencio no hubo más ruido que el también intemporal de los grillos. El fácil pensamiento Estoy en mil ochocientos y tantos dejo de ser unas cuantas aproximativas palabras y se profundizó a realidad. Me sentí muerto, me sentí percibidor abstrato del mundo (...).No cref, no, haber remontado las presuntivas aguas del Tiempo, más bien me sospeché possedor del sentido (...) de la palabra eternidad.

Sólo después alcancé a definir esa imaginación. La escribo, ahora, asti Esa pura representación de hechos homogéneos - noche en serenidad, parecita límpida, olor provinciano de la madreselva, barro fundamental - no es meramente idéntica a la que hubo en esa esquina hace tantos años; es, sin parecidos ni repeticiones, la misma. El tiempo, si podemos intuir esa identidad, es una delusión; (...) la vida es demasiado pobre para no ser también inmortal."

(Historia de la Eternidad)

Se fixamos para referência, $\mathrm{sg}^{2}$, do trecho aqui transcrito, o relato introdutório, la tarde que precedió a esa noche - a tarde do passeio do narrador pelas ruas de Barracas -, então os sentidos pressupostos que constituem os referentes possíveis para essa referência são os de que o 
passeio dessa tarde foi contemporaneo, simultaneamente, (a) daquele fim de dia que precedeu a noite mencionada, (b) da infância do narrador, (c) do Dom Quixote, (d) dos tempos pré-colombianos, anteriores à Conquista, (e) e de mil oitocentos e tantos. Essa "contemporaneidade transtemporal" do conto está fundada sobre um argumento paradoxal: o de que as circunstâncias de ancoragem daquela noite eram nāo somente idênticas às de outros entardeceres, senăo que eram as mesmas.

Freqüentemente os contextos pressupostos funcionam na obra de Borges como o espaço de localização de arquétipos e símbolos míticos construidos sobre diversas figuras da repetiçāo que, fundamentadas em um argumento paradoxal semelhante a esse - um enigma da cabala, uma proposição herética, um dogma perverso, uma revelação gnóstica, uma hipótese esotérica - sáo a seguir aplicadas aos componentes da discursivização, operando a identificaçäo dos atores, dos espaços e dos tempos narrativos. É, pelo menos, o que acontece em El Inmortal, onde Borges trabalha uma divertida doutrina da compensação, enunciada na fórmula "não há coisa que não esteja compensada por outra", para, em seguida, armar o conto como um silogismo: admitida a premissa maior consubstanciada nesse argumento das compensaçóes, segue-se (como, de resto, viu-se acontecer nos exemplos retro citados):

- que todas as coisas se repetem infinitamente, como réplicas umas de outras:

"No hay cosa que no esté como perdida entre

innumerables espejos" (El Inmortal)

- de modo que a História é uma escandalosa sucessão dos mesmos acontecimentos,

"Nada puede ocurrir una sola vez" (El Inmortal),

essa regra da repetição sendo apta, portanto, para ser elevada, muito naturalmente, à condição de procedimento de composição.

É, de fato, com o emprego dela, que Borges costuma estabelecer o necessário vínculo entre o nível de manifestação discursiva e o nível imanente, semionarrativo, de seus relatos. Assim, aplicado aos componentes da discursivização, o procedimento da repetição do arquétipo mítico localizado no contex to pressuposto produzirá:

- a identidade actancial, mítica, de nível imanente, de atores históricos bem diferentes, a nível da manifestação:

"Un solo hombre inmortal es todos los hombres" (El inmortal)

"Damián, como gaucho, tenía obligación de ser Martin Fierro." (La Otra Muerte)

"Al errar por las lentas galerfas

Suelo sentir con vago horror sagrado

Que soy el otro, el muerto, que habra dado

Los mismos pasos en los mismos días."

(Poema de los Dones) 
- a identidade extensional, mítica e imanente, de espaços históricos diferentes, a nivel de manifestaçāo:

"Todas las partes de la casa están muchas veces, cualquier lugar es otro lugar" (La Casa de Asterión)

- a identidade duracional, mítica e imanente, de tempos históricos diferentes, a nível da manifestaçāo:

"Nada puede ocurrir una sola vez..." (El Inmortal)

"... Otalora comprende, antes de morir, que desde el principio lo han traicionado, que ha sido condenado a muerte, que le han permitido el (...) triunfo por que ya lo daban por muerto, porque para Bandeira estaba muerto."

(El Muerto)

\section{RESUMEN}

El trabajo intenta aclarar el concepto de isotopla figurativa del mensageen cuanto sentido contextual, que resulta de la aplicación de los mecanismos de replicabilidad y citatividad a las distintas partes del discurso. Éstas se asocian, asf, en el proceso de lectura, como una espécie de replicas unas de otras, cuyo sentido solo se percibe cuando uno las lee complementariamente referidas unas a otras, como segmento relatum citante (la réplica que se está a leer como esto, aquf, ahora) vs. segmento correlato citado (el de que uno se acuerda, al leer el relation, como aquello que leyb, alla, entonces, en

(1) en otra parte del mismo mensage (el correlato funciona entonces como un intratexto, o contexto puesto - es decir, en construcción, por la lectara, en el presente discurso) 0

(2) en otro mensaje (el correlato constituye, en ese caso, un intertexto, o contexto de presuposicion).

A continuación se estudian algunos de los intertextos basados en mitologemas argentinos de que derivan, a la vez, la pluri-isotopía y la típica figuratividad de los relatos de Jorge Luís Borges. 